\title{
Positive automaintenance does not produce sustained pecking to a tone
}

\author{
RODLYN B. BOE and STEPHEN WINOKUR \\ Texas Christian University, Fort Worth, Texas 76129
}

\begin{abstract}
Pigeons were exposed to a compound of 5 sec of $2,000-\mathrm{Hz}$ tone immediately followed by 5 -sec access to food on a variable-time (VT) 1-min schedule. Little or no pecking at the speaker from which the tone came was observed in 15 birds. Six other birds were exposed to a compound of $5 \mathrm{sec}$ of keylight immediately followed by $5 \mathrm{sec}$ of food on a VT 1-min schedule. The keylight and food pairings generated large amounts of sustained keypecking by all six birds. These results favor a species-specific preparedness interpretation rather than a Pavlovian conditioning explanation of automaintenance.
\end{abstract}

Several investigators have described procedures that induce food-deprived pigeons to peck at a lighted response key when food is briefly presented following a short change of the illumination of the key. In autoshaping (Brown \& Jenkins, 1968), the first peck during each period of changed illumination restores the key to its former state and delivers food immediately. In negative automaintenance (Williams \& Williams, 1969), responses during the period of changed illumination cancel programmed food deliveries. In a procedure that may be called positive automaintenance, responses to the key have no programmed consequences (Gamzu \& Williams, 1971). Each of the three different procedures has been called by the names of the others, which has doubtless increased the difficulty of understanding the processes involved. It should be noted that positive automaintenance is procedurally identical to Pavlovian (respondent, classical) conditioning; the other two procedures are not.

Attempts to explain why responding is generated by these procedures have suggested that such responding may be the result of (1) Pavlovian conditioning (Gamzu \& Williams, 1971), (2) a species-specific tendency of the pigeon (Brown \& Jenkins, 1968), (3) adventitious operant conditioning (Brown \& Jenkins, 1968), or (4) stimulus generalization (Logan, 1971). The Pavlovian conditioning interpretation is generally favored in recent papers on the subject (e.g., Schwartz \& Gamzu, 1977).

In the traditional account of classical (Pavlovian) conditioning, most organisms are indifferent as to which stimuli are to be used as conditioned stimuli. Kimble

This work was supported by Grants PS-6891, PS-6977, and PS-7453 from the TCU Research Foundation. Some of the data reported here were presented at the Sixteenth Annual Meeting of the Psychonomic Society, Denver, 1975. Request reprints from S. Winokur, Psychology Department, Texas Christian University, Fort Worth, Texas 76129. R. B. Boe had moved to the J. F. Kennedy Institute of the Johns Hopkins University, when he unexpectedly died. A draft of this paper was found in his effects and completed by Winokur at the request of Mrs. Boe.
(1961) reported that various investigators were able to use hissing noises, electric fans, metronomes, bells, buzzers, lights, colored papers, and line drawings of geometrical forms as conditioned stimuli.

Bilbrey and Winokur (1973), however, attempted to condition keypecking using autoshaping but employed a 10 -sec tone as the CS, and they found that none of their birds would keypeck. The same birds were then given autoshaping training using key illumination as the CS, and all birds learned to keypeck. When the same birds were again given autoshaping training using a tone as the CS, they still failed to keypeck.

A possible defect of Bilbrey and Winokur's (1973) study might be that there was no close spatial relationship between the tone and the key. Hence, a conditioned response established to the tone would be unlikely to be directed to the key, because the key and the speaker from which the tone emanated had different locations. The experiment to be reported here investigated positive automaintenance with a tone as a conditioned stimulus to which recordable responses could be made.

\section{METHOD}

\section{Subjects}

Twenty-one naive White Carneaux pigeons, obtained from Palmetto Pigeon Plant, were maintained at $80 \%$ of their freefeeding weights throughout the experiment.

\section{Apparatus}

A commercial pigeon chamber was equipped with a 5-cmdiam circular speaker that was attached to a microswitch. The speaker projected $5 \mathrm{~cm}$ out from the center of the front panel and was $20 \mathrm{~cm}$ above the floor and $13 \mathrm{~cm}$ above the food hopper opening. Recording and scheduling equipment of the type described by Ferster and Skinner (1957) was located in an adjacent room.

\section{Procedure}

Prior to the experiment proper, the pigeons were trained to approach and eat from the lighted food hopper each time it was operated. Food presentations lasted $5 \mathrm{sec}$. During hopper training, the speaker was removed from the chamber. Once each 
Table 1

Number of Responses per Session for Each Bird

\begin{tabular}{|c|c|c|c|c|c|c|c|c|c|c|c|c|c|c|c|c|c|c|c|c|c|c|c|c|c|c|c|c|c|c|}
\hline \multirow{3}{*}{$\begin{array}{l}\text { Ses- } \\
\text { sion }\end{array}$} & \multicolumn{30}{|c|}{ Pigeon } \\
\hline & \multicolumn{2}{|c|}{$\mathrm{W}-41$} & \multicolumn{2}{|c|}{ W-55 } & \multicolumn{2}{|c|}{ W-56 } & \multicolumn{2}{|c|}{ W-57 } & \multicolumn{2}{|c|}{ W-58 } & \multicolumn{2}{|c|}{ W-59 } & \multicolumn{2}{|c|}{ W-60 } & \multicolumn{2}{|c|}{ W-61 } & \multicolumn{2}{|c|}{ W-1 } & \multicolumn{2}{|c|}{ W-2 } & \multicolumn{2}{|c|}{ W-3 } & \multicolumn{2}{|c|}{ W-62 } & \multicolumn{2}{|c|}{$W-63$} & \multicolumn{2}{|c|}{ W-64 } & \multicolumn{2}{|c|}{$\mathrm{W}-65$} \\
\hline & D & B & D & B & D & B & D & B & D & B & D & B & D & B & D & B & D & B & D & B & D & B & D & B & D & B & $\mathrm{D}$ & B & D & B \\
\hline 1 & 0 & 0 & 0 & 0 & 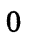 & 1 & 0 & 0 & 4 & 2 & 0 & . & & 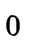 & & 69 & 0 & 0 & 0 & 0 & 0 & 0 & 0 & 0 & 0 . & & 0 & 0 & 1 & 6 \\
\hline 2 & 0 & 0 & 0 & 0 & 0 & 2 & 0 & 0 & 0 & 2 & 0 & 0 & 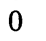 & 0 & 0 & 2 & 0 & 0 & 0 & 0 & 0 & 0 & 0 & 0 & 0 & & 0 & 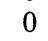 & 0 & \\
\hline 3 & 0 & 0 & 0 & 2 & 0 & 1 & 0 & 0 & 0 & 0 & 2 & 0 & 0 & 0 & 0 & 6 & 0 & 0 & 0 & 0 & 0 & 0 & 0 & 8 & 0 & 1 & 0 & 1 & 0 & ) \\
\hline 4 & 0 & 0 & 0 & 0 & 0 & 0 & 0 & 0 & 0 & 0 & 0 & 0 & 0 & 0 & 0 & 43 & 0 & 0 & 0 & 0 & 0 & 0 & 0 & 0 & 0 & 1 & 0 & 2 & 0 & 0 \\
\hline 5 & 0 & 0 & 0 & 0 & 0 & 0 & 0 & 0 & 0 & 0 & 0 & 0 & 0 & 3 & 0 & 6 & 0 & 0 & 0 & 0 & 0 & 0 & 0 & 1 & 0 & 0 & 0 & 10 & 0 & 0 \\
\hline 6 & 0 & 0 & 0 & 0 & 0 & 0 & 0 & 0 & 0 & 0 & 0 & 0 & 0 & 0 & 0 & 0 & 0 & 0 & 0 & 0 & 0 & 0 & 0 & 0 & 0 & 0 & 0 & 7 & 0 & 0 \\
\hline 7 & 0 & 0 & 0 & 0 & 0 & 0 & 0 & 0 & 0 & 0 & 0 & 4 & 0 & 0 & . & 2 & 0 & 0 & 0 & 0 & 0 & 0 & 0 & 0 & 0 & 0 & 0 & 4 & 0 & 2 \\
\hline 8 & 0 & 0 & 0 & 2 & 0 & 0 & 0 & 0 & 0 & 3 & 0 & 6 & 0 & 0 & 0 & 7 & 0 & 0 & 0 & 0 & 0 & 0 & 0 & 0 & 0 & 0 & 0 & 1 & 0 & 0 \\
\hline 9 & 0 & 0 & 0 & 0 & 0 & 1 & 0 & 0 & 0 & 0 & 0 & 0 & 0 & 1 & 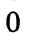 & 5 & 0 & 0 & 0 & 0 & 0 & 0 & 0 & 1 & 0 & 0 & 0 & 19 & 0 & 0 \\
\hline 10 & 0 & 0 & 0 & 1 & 0 & 0 & 0 & 0 & 0 & 0 & 0 & 0 & 0 & 0 & 0 & 8 & 0 & 0 & 0 & 0 & 0 & 0 & 0 & 1 & 0 & 0 & 11 & 57 & 0 & 0 \\
\hline
\end{tabular}

Note $-D=$ number of responses made during tone presentation; $B=$ number of responses made between tone presentations.

pigeon was observed to eat from the food hopper, it was given 60 additional food presentations.

During the experiment proper, 15 pigeons were exposed to a combination of $5 \mathrm{sec}$ of a $2,000-\mathrm{Hz}$ tone followed immediately by $5 \mathrm{sec}$ of access to food on a VT 1 -min schedule. Tone intensities were $80 \mathrm{~dB}$. Pecks at the speaker were recorded, but had no effects on the experimental procedure. Daily sessions consisted of 40 tone-food presentations. The pigeons received all of their food during the experimental sessions. This procedure was in effect for 10 consecutive days.

Six other (control) pigeons were subjected to a procedure that was similar except that a 5 -sec illumination of a standard response key by a white light replaced the tone. The $1.9-\mathrm{cm}-$ diam response key was located behind the front panel, but otherwise in the same position as the speaker. The control birds received 50 light-food pairings per daily session for 8 consecutive days.

\section{RESULTS AND DISCUSSION}

Table 1 shows the number of times that each pigeon pecked at the speaker either during tone presentations or between tone presentations. Table 2 displays the number of times that the control birds pecked at the response key either when it was lit or between lightings. It is clear that none of the birds consistently pecked at the speaker when the tone was presented. Pigeons W-61 and W-64 pecked at the speaker more than the other birds did. We do not believe that this indicated that these two birds' pecking was the result of automaintenance. Notice that most of their pecks occurred between tones, and their pecking was much less than that found as a result of positive automaintenance with a lighted key as the stimulus. Compare these data with the number of pecks (1) during keylight presentations and (2) between keylight presentations by control birds. W-61 and W-64's pecking at the speaker was most likely due to adventitious operant conditioning, which would produce a small amount of behavior that would be very poorly correlated with intermittent changes in the environment. That is, although pigeons do not ordinarily peck at lit response keys in the absence of experimental procedures, some birds will peck at a key prior to any conditioning procedures. In this experiment, the two birds, may have pecked at the speaker without conditioning and just prior to a delivery of food. Such a food delivery may have produced adventitious conditioning of speaker pecking. This explanation is supported by our observation that all of the birds that pecked displayed what appeared to be superstitious behaviors, for example, rapid packing back and forth in front of the

Table 2

Number of Responses per Session for Each Control Bird

\begin{tabular}{|c|c|c|c|c|c|c|c|c|c|c|c|c|}
\hline \multirow[b]{3}{*}{ Day } & \multicolumn{12}{|c|}{ Pigeon } \\
\hline & \multicolumn{2}{|c|}{ C-3 } & \multicolumn{2}{|c|}{ C-8 } & \multicolumn{2}{|c|}{ C-13 } & \multicolumn{2}{|c|}{ C-2 } & \multicolumn{2}{|c|}{ C-7 } & \multicolumn{2}{|c|}{ C-12 } \\
\hline & D & B & D & B & D & B & D & B & D & B & D & B \\
\hline 1 & 327 & 106 & 189 & 259 & 209 & 5 & 89 & 8 & 125 & 43 & 209 & 5 \\
\hline 2 & 407 & 28 & 464 & 48 & 438 & 0 & 184 & 6 & 434 & 7 & 483 & 0 \\
\hline 3 & 485 & 30 & 515 & 19 & 485 & 11 & 243 & 4 & 302 & 1 & 485 & 11 \\
\hline 4 & 284 & 7 & 566 & 28 & 335 & 9 & 80 & 1 & 187 & 1 & 335 & 9 \\
\hline 5 & 307 & 5 & 584 & 25 & 508 & 11 & 231 & 3 & 143 & 0 & 508 & 11 \\
\hline 6 & 282 & 9 & 620 & 27 & 253 & 13 & 181 & 2 & 72 & 0 & 253 & 13 \\
\hline 7 & 537 & 14 & 575 & 22 & 284 & 6 & 119 & 1 & 90 & 0 & 284 & 6 \\
\hline 8 & 48 & 25 & 571 & 22 & 312 & 7 & 183 & 2 & 47 & 0 & 312 & 7 \\
\hline
\end{tabular}

Note $-D=$ number of responses during keylight presentations; $B=$ number of responses between keylight presentations. The food hopper lamp burned out on Day 8 for Pigeon $C-3$. 
food hopper, pecking at the floor, standing before the food hopper, and swaying from side to side.

If positive automaintenance is a classical conditioning process, the birds should have been conditioned to peck the speaker during tone presentations. Wasserman, Markman, and Hearst (Note 1) predicted that a diffuse cue, such as an auditory stimulus, would be ineffective in autoshaping pigeons' keypecking behavior. It seems, however, that in the present experiment diffuseness of an auditory cue is a questionable explanation for the lack of responding to the speaker, since the tone emanated from a small speaker in a conspicuous location directly above the food hopper.

Steinhauer, Davol, and Lee (1976) have argued that autoshaping is sensitive to the number of magazine training trials presented prior to the initiation of autoshaping. These authors have also suggested (Steinhauer, Davol, \& Lee, 1977) that Bilbrey and Winokur (1973) were unable to produce autoshaped keypecking with a tone because the birds in their experiment were insufficiently magazine trained. It cannot be objected that the pigeons in the present study were insufficiently magazine trained. Here, each pigeon was magazine trained until he was observed to eat each time the magazine was presented and then was given 60 additional food presentations, considerably more magazine training than that given Steinhauer et al.'s (1976, Experiment 2) most extensively trained birds.

In a later experiment (Steinhauer et al., 1977), pigeons were given a total of 90 magazine training trials, followed by autoshaping with a $1,000-\mathrm{Hz}$ tone as the prefood stimulus. The tone that was the prefood stimulus in the autoshaping was presented whenever the food hopper was activated in both magazine training and in autoshaping proper. The birds were observed to peck at the response key from which the tone emanated. Steinhauer et al. have argued that their findings indicate that generalization plays an important role in autoshaping, and, hence, in failures to obtain autoshaping with a tone.

We believe, however, that the results of Steinhauer et al. (1977) have no bearing upon the present study and, moreover, illustrate the importance of the terminological distinctions made in this paper. Steinhauer et al. (1977) used a special autoshaping procedure designed to capitalize on whatever generalization might occur between the stimuli associated with food presentations and those presented in autoshaping. Wasserman and McCracken (1974) used positive automaintenance, despite the title of their paper, and showed that stimulus generalization was not responsible for sustained keypecking. Their procedure (Experiment 2) was very similar to that of Steinhauer et al. (1977), save that lights were employed rather than tones.

The discrepancy between the results of the present study and those of Steinhauer et al. (1977) may be explained as follows (even though it is not the major purpose of the present paper to do so). The present authors (1) used automaintenance, (2) allowed the attainment of steady states of behavior by their subjects, and (3) presented extensive data concerning the amount of pecking throughout the experiments. Steinhauer et al. used autoshaping as their procedure and trials to the first peck as their dependent variable. These differences in procedure might have produced the differing results for the following reasons.

Autoshaping is similar to positive automaintenance until the pigeon first pecks at the key. Once the bird pecks, he is subjected to a discrete-trial continuous reinforcement schedule. Thus, a generalized disposition to peck may be responsible for the first peck in the Steinhauer et al. (1977) experiment, but subsequent pecking was increased and maintained by responsecontingent continuous reinforcement. However, in the present experiment, positive automaintenance was used. This procedure does not allow any response-contingent continuous reinforcement. Hence, Steinhauer et al. (1977) response-contingently reinforced any weak generalized responding and generated further extensive responding by continuous reinforcement. In the present experiment, automaintenance was carried out for several days and showed that responding was zero or near zero and far less than that generated and maintained by positive automaintenance with a lit key as stimulus.

It should be recalled that only positive automaintenance is procedurally identical with classical (Pavlovian, respondent) conditioning. Use of procedures such as autoshaping and measures such as trials to the first peck obscure the important issues involved here.

In summary, the present experiment has shown that pigeons will not peck at the source of a tone presented in positive automaintenance. This failure to peck is not the product of insufficient magazine training or lack of stimulus generalization.

This result suggests that pecking at a lit key that is generated by positive automaintenance is not simply a matter of classical (Pavlovian) conditioning. This suggestion is further supported by the experiment of Winokur and Frank (Note 2) that showed that positive automaintenance produced sustained high rates of pecking at a lit key even though keylight presentations were followed by food less than $7.7 \%$ of the times that they occurred. It has been reported (Kimble, 1961) that responses conditionable by Pavlovian procedures will not be conditioned at all if stimulus-stimulus pairings occur with a frequency below $20 \%$. It thus seems that there are two sources of evidence that positive automaintenance is not a classical (Pavlovian) conditioning process.

However, it might be argued that the results of the experiment reported here and those of Winokur and Frank (Note 2) merely demonstrate a constraint on the Pavlovian conditioning of pecking in pigeons. It would then be argued that the processes underlying the 
conditioning of the pigeon's keypeck are fundamentally the same as those underlying conditioning of the galvanic skin response, eye blinks, or salivation. The difference between the keypeck and the other responses, according to this argument, is that the others break down under extended schedules of intermittent reinforcement and will condition to auditory stimuli, whereas the keypeck will be maintained on extended schedules of intermittent reinforcement and will not be conditioned to auditory stimuli.

Such an argument is specious, because it implicitly defines operant conditioning as a special (constrained) form of Pavlovian conditioning. The argument implies, for example, that no experiment on intact organisms could demonstrate the existence of two functionally separate conditioning procedures. Acceptance of the argument further implies that all the properties of operantly conditioned keypecking demonstrated by Ferster and Skinner (1957) were really due to Pavlovian conditioning with special constraints or boundary conditions applying to the keypeck.

Seligman (1970) has proposed a hypothesis that appears to account for the results of experiments thus far reported. He has argued that pigeons are genetically prepared to associate visual stimuli with food. Seligman has not claimed that pigeons are unprepared to associate auditory stimuli with food, but the results reported here are consistent with that extension of his hypothesis. We know of no results reported to date that contradict such a hypothesis.

\section{REFERENCE NOTES}

1. Wasserman, E. A., Markman, B. S., \& Hearst, E. Autoshaping and contextual illumination: Selection of the behavior and its orientation toward the most predictive cue. Paper presented at the annual meeting of the Psychonomic Society, St. Louis, November 1971.
2. Winokur, S., \& Frank, A. Automaintenance of pigeon's keypecking on a variable ratio. Paper presented at the annual meeting of the Psychonomic Society, St. Louis, November 1973.

\section{REFERENCES}

Bilbrey, J. L., \& Winokur, S. Controls for and constraints on autoshaping. Journal of the Experimental Analysis of Behavior, 1973, 20, 321-332.

Brown, P. L., \& Jenkins, H. M. Auto-shaping the pigeon's key peck. Journal of the Experimental Analysis of Behavior, $1968,11,1-8$.

Ferster, C. B., \& Skinner, B. F. Schedules of reinforcement. New York: Appleton-Century-Crofts, 1957.

Gamzu, E., \& Williams, D. R. Classical conditioning of a complex skeletal response. Science, 1971, 171, 923-925.

KImBLe, G. A. Hilgard and Marquis' conditioning and learning. New York: Appleton-Century-Crofts, 1961.

LogAN, F. A. Incentive theory, reinforcement and education. In R. Glaser (Ed.), The nature of reinforcement. New York: Academic Press, 1971.

Schwartz, B., \& Gamzu, E. Pavlovian control of operant behavior. In W. K. Honig \& J. E. R. Staddon (Eds.), Handbook of operant behavior. Englewood Cliffs, N.J: Prentice-Hall, 1977.

Seligman, M. E. P. On the generality of the laws of learning. Psychological Review, 1970, 77, 406-418.

Steinhauer, G. D., Davol, G. H., \& Lee, A. Acquisition of the autoshaped key peck as a function of the amount of preliminary magazine training. Journal of the Experimental Analysis of Behavior, 1976, 25, 355-359.

Steinhauer, G. D., Davol, G. H., \& Lee, A. A procedure for autoshaping the pigeon's key peck to an auditory stimulus. Journal of the Experimental Analysis of Behavior, 1977, 28, 97-98.

Wasserman, E. A., \& McCracken, S. B. The disruption of autoshaped key pecking in the pigeon by food-tray illumination. Journal of the Experimental Analysis of Behavior, 1974, 22, $39-45$.

Williams, D. R., \& Williams, H. Auto maintenance in the pigeon: Sustained pecking despite contingent nonreinforcement. Journal of the Experimental Analysis of Behavior, 1969, 12, 511-520.

(Received for publication April 11, 1979.) 